\title{
Avaliação da estimulação e apoio no ambiente familiar oferecido à criança com paralisia cerebral
}

\section{Evaluation of stimulation and support in the family environment offered to children with cerebral palsy}

\author{
Tássia Lopes de Azevedo', Patrícia Carla de Souza Della Barba²
}

http://dx.doi.org/10.11606/issn.2238-6149.v28i2p198-205

\begin{abstract}
Azevedo TLA, Della Barba PCS. Avaliação da estimulação e apoio no ambiente familiar oferecido à criança com paralisia cerebral. Rev Ter Ocup Univ São Paulo. 2017 maio-ago.;28(2):198-205.

RESUMO: A família é um espaço privilegiado para o desenvolvimento do indivíduo e da sociedade. Assim, o objetivo desta pesquisa foi avaliar a frequência da estimulação e apoio oferecido à criança no ambiente familiar, baseado na perspectiva dos pais. Participaram 17 mães e dois pais de crianças com paralisia cerebral com idade entre um a 12 anos. Os participantes foram entrevistados em centros de atendimento à criança, instituição educacional e no próprio domicílio. O questionário aplicado foi o EC-Home. Os dados quantitativos foram analisados por meio de métodos descritivos (frequência absoluta, relativa e média aritmética). Os resultados demonstraram que os pais são responsivos às necessidades dos filhos e tentam manter-se próximos deles na maior parte do tempo; oferecem estímulos, principalmente relacionados aos aspectos acadêmicos e de linguagem. Conclui-se que os dados podem auxiliar outras pesquisas na proposição de programas de intervenção focados em famílias, a fim de maximizar a estimulação que pode ser oferecida aos filhos e empoderar os pais, apontados como os principais agentes para o desenvolvimento infantil.
\end{abstract}

DESCRITORES: Paralisia cerebral; Família; Estimulação física; Meio ambiente; Crianças com deficiência.
Azevedo TLA, Della Barba PCS. Evaluation of stimulation and support in the family environment offered to children with cerebral palsy. Rev Ter Ocup Univ São Paulo. 2017 MayAug.;28(2):198-205.

\begin{abstract}
The family is a privileged space for the development of the individual and society. Thus, the objective of this research was to evaluate the frequency of stimulation and support offered to the child in the family environment, based on the parents' perspective. The participants were 17 mothers and two fathers of children with cerebral palsy aged one to 12 years. Participants were interviewed at child care centers, educational institution and at home. The questionnaire applied was EC-Home. Quantitative data were analyzed using descriptive methods (absolute frequency, relative and arithmetic mean). The results showed that the parents are responsive to the needs of children, and attempt to stay near the same most of the time; yet, they offer incentives, mainly related to academic aspects and language. It concludes that the data can help further research on investment focused intervention programs for families in order to maximize the stimulation that can be offered to children and empower parents, identified as the main agents for child development.
\end{abstract}

KEYWORDS: Cerebral palsy; Family; Physical stimulation; Environment; Disabled children.

O conteúdo apresentado é um recorte da pesquisa intitulada "Avaliação da Interação Cuidador-Criança sobre os aspectos do Brincar", Trabalho de conclusão do curso de especialização em neurologia infantil da Universidade Estadual de Campinas.

1. Terapeuta Ocupacional, Mestre e Doutoranda em Educação Especial pela Universidade Federal de São Carlos - UFSCar. Especialista em Reabilitação em Deficiência Visual e em Reabilitação Aplicada à Neurologia Infantil pela Universidade Estadual de Campinas - UNICAMP. Professora Substituta no Departamento de Terapia Ocupacional na UFSCar (2014-2015). E-mail: tassialazevedo@gmail.com

2. Terapeuta Ocupacional, Pós-doutorado em Estudos da Criança no Instituto de Educação da Universidade do Minho, Braga, Portugal. Mestre e Doutora em Educação Especial pela Universidade Federal de São Carlos. Docente Adjunto IV do curso de graduação em Terapia Ocupacional da Universidade Federal de São Carlos, do Programa de Pós-Graduação em Terapia Ocupacional (PPGTO) e do

Programa de Pós-Graduação em Gestão da Clínica (PPGGC). E-mail: patriciadellabarba@yahoo.com.br

Endereço para correspondência: Universidade Federal de São Carlos - Departamento de Terapia Ocupacional da UFSCar. Rodovia Washington Luís, Km 235 - SP-310. São Carlos, SP, Brasil. CEP: 13565-905. 


\section{INTRODUÇÃO}

Paralisia Cerebral (PC) abrange um
conjunto de afecções que comprometem o
sistema nervoso central imaturo. Trata-se de distúrbios motores não progressivos (tônus e postura) secundários à lesão do cérebro em desenvolvimento ${ }^{1}$. Como consequência a criança pode desenvolver fraqueza muscular, dificuldade de controle da musculatura, restrição de amplitude de movimento e alterações de tônus e sensibilidade ${ }^{2}$.

As manifestações clínicas da PC podem resultar em limitações nas atividades e tarefas cotidianas. Estas tarefas incluem as atividades de autocuidado como alimentação, higiene pessoal, comunicação e atividades de mobilidade, além das atividades de características sociais e cognitivas, como o brincar com brinquedos e com outras crianças e frequentar a escola ${ }^{3-6}$. Muitas destas atividades são desempenhadas com a ajuda dos pais, que passam a ter múltiplas responsabilidades.

$\mathrm{O}$ enfrentamento dos problemas de saúde decorrentes da condição clínica da PC pode causar alterações na saúde e na qualidade de vida dos pais ${ }^{7}$.

Considerando que o sistema familiar exerce influência sobre o desenvolvimento, devido a maior proximidade e convivência com seus filhos, a parceria entre pais e profissionais deve ser considerada ${ }^{6-8}$.

Os pais estabelecem um ambiente acolhedor e organizam contextos favoráveis aos seus filhos, proporcionam mecanismos de proteção diante de fatores ameaçadores que usualmente as crianças estão expostas. Portanto, as interações estabelecidas no microssistema familiar são as que trazem implicações mais significativas para o desenvolvimento infantil, embora outros sistemas sociais também contribuam ${ }^{8-9}$.

O ambiente familiar é um contexto que atua no desenvolvimento infantil, principalmente de crianças com deficiência, que necessitam de maior envolvimento em seus cuidados e na sua estimulação ${ }^{10}$.

Ao pesquisar famílias de crianças com deficiência, Azevedo ${ }^{11}$ apontou que as mães se consideravam principais responsáveis pelas tarefas domésticas e cuidados diários da criança. A rede social de apoio das mães era composta em sua maioria pelos avós. Em relação aos pais, 50\% auxiliavam suas companheiras nos afazes do lar. Diante deste cenário, metade dos participantes relatou que apresentam algum sintoma indicativo de estresse ${ }^{11}$.

Outro estudo que investigou os recursos e características do ambiente domiciliar somados às necessidades dos pais de crianças com deficiência, demonstrou que os participantes necessitavam de maior informação sobre os serviços e os apoios que o filho poderia se beneficiar no futuro. Além disso, careciam de auxílio profissional para compreender a deficiência da criança e necessitavam de suporte a fim de obter serviços de apoio social e educativo ao filho. Concluiu-se que os pais sentiam-se desprovidos de ajuda para resolver problemas financeiros e pessoais ${ }^{12}$.

A influência dos pais no desenvolvimento infantil promove melhores resultados quando estes se envolvem, uma vez que a criança se sente acolhida ao lado de alguém que lhe é familiar?.

Famílias de pessoas com deficiência apresentam características semelhantes a qualquer outra, porém algumas demandas farão com que estas se diferenciem devido a complexidade de sua organização, pela intensidade e conflitos de sentimentos, além das demandas por serviços de apoio9.

A influência familiar tanto pode facilitar como impedir o processo de inclusão da criança com deficiência.

Para desenvolver ambientes apropriados para o desenvolvimento, é necessário que sejam oferecidos suporte e auxílio de serviços que possam proporcionar melhores resultados para as crianças e suas famílias. Estimular a criança no âmbito familiar é fundamental para o desenvolvimento positivo dos aspectos neurológico, psicológico e motor, além de estimular os potenciais infantis ${ }^{11}$.

Uma atividade importante para o desenvolvimento infantil é o brincar, que deve ser facilitado para a criança com deficiência física, a fim de que ela possa exteriorizar os seus sentimentos e explorar as funções motoras, cognitivas e sociais, possibilitando o enfrentamento de situações conflitantes por meio do desenvolvimento de novas habilidades ${ }^{1,8}$.

Em relação a intervenção e objetivos da terapia ocupacional com crianças que apresentam PC, podemos dizer que o papel do terapeuta ocupacional consiste em graduar e adaptar ocupações e atividades, promovendo a aquisição de habilidades e a modificação do ambiente, permitindo que o indivíduo desenvolva competências em seus papéis ${ }^{2-5}$. Além disso, o profissional considera o desempenho de atividades significativas para criança e sua família, assim como a sua participação em diferentes ambientes que irá depender de habilidades físicas, perceptocognitivas e emocionais, além da inter-relação entre essas características e o ambiente ${ }^{2}$.

O presente estudo foi desenvolvido no ambiente domiciliar, com intuito de avaliar a frequência da estimulação e apoio oferecidos à criança, o que incluiu 
questões como: (a) estimulação acadêmica; (b) estimulação da linguagem; (c) responsabilidade parental; (d) modelos comportamentais dos pais aos filhos; (d) variedades dos estímulos oferecidos ao filho; e (e) aceitação da deficiência da criança. Tal pesquisa obteve duração de quatorze meses (janeiro/2015 à fevereiro/2016), e foi desenvolvida em centros de reabilitação, escola especial e domicílio dos pais.

Diante do exposto, acredita-se que ainda há fatores a serem investigados quanto às características do ambiente domiciliar e sua relação com a estimulação de crianças com PC.

\section{OBJETIVOS}

O objetivo deste estudo foi avaliar a frequência da estimulação e apoio oferecidos à criança no ambiente familiar, baseado na perspectiva dos pais.

\section{MÉTODO}

\section{Participantes}

Essa pesquisa foi desenvolvida com 19 genitores (sendo 17 mães e 2 pais) de crianças com paralisia cerebral.

Foram utilizados como critérios de inclusão as crianças apresentarem diagnóstico de paralisia cerebral do tipo hemiparético, diparético ou tetraparético, fornecido pela unidade de saúde na qual realiza acompanhamento médico.

Como critério de exclusão teve-se os pais se recusarem a participar da pesquisa.

\section{Local de Coleta de Dados}

A coleta de dados ocorreu em centros de reabilitação, escola especial e domicílio da população-alvo.

Considerou-se a disponibilidade e preferência dos pais para os locais de coleta da pesquisa. Pais de crianças com deficiência, muitas vezes apresentam pouco tempo disponível, pois dividem os seus compromissos profissionais, familiares e domésticos, com as necessidades reabilitacional, escolar e cotidiana da criança.

\section{Medidas Avaliativas}

Foi utilizado o Inventário EC-Home (Early Childhood - The Home Observation ${ }^{13}$ traduzido para o contexto brasileiro por Martins et al. ${ }^{14}$ ).

$\mathrm{O}$ instrumento foi elaborado por Caldwel e Bradley $^{13}$, e traduzido para o contexto brasileiro por Martins et al. ${ }^{14}$.
Estudos nacionais mostraram evidências sobre a validade do Inventário EC-Home, porém indicaram limitações e dificuldades em relação à tradução e ambiguidade dos itens, o que requer investimento em pesquisas que apontam a necessidade de se aprofundar na validação dos itens ao contexto brasileiro ${ }^{14-15}$.

O inventário EC-Home avalia a estimulação e apoio à criança no ambiente familiar, e é composto por 47 subtópicos, distribuídos em sete itens: (1) materiais de aprendizagem (onze subtópicos); (2) estimulação da linguagem (sete subtópicos); (3) responsabilidade parental (sete subtópicos); (4) estimulação acadêmica (cinco subtópicos); (5) modelagem (cinco subtópicos); (6) variedade de estímulo (oito subtópicos); e (7) aceitação da criança (quatro subtópicos).

$\mathrm{O}$ instrumento original é direcionado para ser preenchido por meio de observação.

Para este estudo o inventário passou por adaptações, sendo que os tópicos e subtópicos foram modificados para o formato de questões alternativas (verdadeiro ou falso) e foi aplicado em forma de entrevista.

Na versão final do questionário, permaneceram 47 perguntas. As questões que compunham a escala ambiente fisico foram retiradas por serem direcionadas inteiramente a um observador, sem possibilidade de adaptação.

\section{Aspectos éticos e procedimentos de coleta de dados}

O projeto foi enviado ao Comitê de Ética em Pesquisa da Universidade Estadual de Campinas (UNICAMP), e aprovado mediante o parecer número 38430514.8 .0000 .5404$.

Posteriormente à aprovação do projeto pelo Comitê de Ética da UNICAMP, a pesquisadora entrou em contato com a Secretaria da Educação, Centro de Reabilitação e Escola de Educação Especial do Município de Campinas - SP.

Ao obter o consentimento dos dirigentes, a pesquisadora divulgou o estudo em instituições que atendiam crianças com deficiência física. Foi estabelecido o contato com os pais via telefone.

Os participantes receberam juntamente com os Termos de Consentimento Livre e Esclarecido, informações acerca dos objetivos da pesquisa. Foi assegurado o sigilo da identidade dos participantes e estes tiveram total autonomia em relação à participação no estudo.

Com os pais que se interessaram em participar da pesquisa, agendou-se um encontro para responder ao Inventário EC-Home, que foi preenchido em forma de entrevista (realizada num tempo médio de 15 minutos). 
Anteriormente à participação efetiva dos pais na pesquisa, solicitou-se a confirmação do laudo diagnóstico das crianças-alvo.

\section{Análise de dados}

Por meio do Inventário EC-HOME Adaptado foram coletados dados quantitativos tabulados e analisados por estatística descritiva, através da frequência absoluta e relativa dos itens verdadeiros, e média aritmética.

\section{RESULTADOS}

A Tabela 1 apresenta a frequência relativa e absoluta da amostra estudada.

Tabela 1 - Caracterização da amostra estudada

\begin{tabular}{llcc}
\hline CARACTERÍSTICAS & FA & FR \\
\hline \multirow{2}{*}{ Gênero das Crianças } & Masculino & 11 & $58 \%$ \\
& Feminino & 08 & $42 \%$ \\
\hline \multirow{2}{*}{ Diagnóstico das } & Diparético & 09 & $47 \%$ \\
Crianças & Tetraparético & 07 & $37 \%$ \\
& Hemiparético & 03 & $16 \%$ \\
\hline \multirow{2}{*}{ Gênero dos Genitores } & Feminino & 17 & $89,5 \%$ \\
& Masculino & 02 & $10,5 \%$ \\
\hline \multirow{5}{*}{ Escolaridade das Mães } & Analfabeto & 03 & $17,5 \%$ \\
& Fundamental & 06 & $35 \%$ \\
& Médio Incompleto & 05 & $30 \%$ \\
& Médio Completo & 03 & $17,5 \%$ \\
\hline \multirow{2}{*}{ Escolaridade dos Pais } & Fundamental & 01 & $50 \%$ \\
& Incompleto & & \\
& Médio Completo & 01 & $50 \%$ \\
\hline \multirow{2}{*}{ Local de Realização da } & Centro Reabilitacional & 09 & $47,4 \%$ \\
& Escola Especial & 06 & $31,6 \%$ \\
& Domicílio & 04 & $21 \%$ \\
\hline
\end{tabular}

Em relação à idade dos participantes, nota-se que as mães apresentaram média de idade de 29,20 anos (idade entre 18 a 41 anos) e os pais média de idade de 32 anos (idade entre 21 a 43 anos).

Quanto à escolarização, a maioria das mães (35\%) relatou ter o ensino fundamental incompleto, seguindo por ensino médio incompleto $(32,4 \%)$. Os pais, por sua vez, cursaram ensino fundamental incompleto $(50 \%)$ e ensino médio completo $(50 \%)$.

Ao avaliar as características dos filhos, observa-se que a média de idade das crianças era de 5,2 anos, sendo que os meninos apresentavam idade entre um a 12 anos e as meninas um a seis anos de idade.

Em relação ao gênero das crianças, nota-se que $58 \%$ eram meninos $(n=11)$ e $42 \%(n=08)$ eram meninas.

Quanto ao diagnóstico, a prevalência foi de PC do tipo diparético, com $47 \%$ das crianças $(n=09)$, seguindo de $\mathrm{PC}$ do tipo tetraparético $(37 \% ; \mathrm{n}=07)$ e hemiparético com $16 \%(\mathrm{n}=03)$.

\section{Descrição da frequência de estimulação e apoio disponíveis à criança no lar}

Os resultados referentes à estimulação e apoio à criança foram apresentados em itens de maior e menor frequência relativa e absoluta dos dados. Utilizou-se como critério de maior frequência as respostas com pontuação acima de $60 \%$, e os itens de menor frequência as respostas que apresentavam pontuação abaixo de $60 \%$.

A Tabela 2 mostra os itens de maior frequência relativa e absoluta da estimulação e apoio familiar à criança com deficiência física.

Tabela 2 - Maior frequência relativa e absoluta sobre a estimulação e apoio dos pais aos filhos no ambiente domiciliar

\begin{tabular}{|c|c|c|}
\hline EC - HOME & FA & FR \\
\hline \multicolumn{3}{|l|}{ MATERIAIS DE APRENDIZAGEM } \\
\hline $\begin{array}{l}\text { A criança possui brinquedos e jogos que permitem a } \\
\text { livre expressão }\end{array}$ & 17 & $89 \%$ \\
\hline O filho é estimulado a aprender formas & 16 & $84 \%$ \\
\hline \multicolumn{3}{|l|}{ ESTIMULAÇÃO DE LINGUAGEM } \\
\hline Estimula o filho a falar e a ouvir & 19 & $100 \%$ \\
\hline Transmite sentimentos positivos ao filho & 19 & $100 \%$ \\
\hline \multicolumn{3}{|l|}{ SER RESPONSIVO } \\
\hline $\begin{array}{l}\text { Interage verbalmente com o filho pelo menos duas } \\
\text { vezes por semana, em um período de meia hora }\end{array}$ & 19 & $100 \%$ \\
\hline $\begin{array}{l}\text { Responde verbalmente às solicitações ou questões da } \\
\text { criança }\end{array}$ & 19 & $100 \%$ \\
\hline Demonstra carinho ao filho durante meia hora por dia & 19 & $100 \%$ \\
\hline \multicolumn{3}{|l|}{ ESTIMULAÇÃO ACADÊMICA } \\
\hline A criança é estimulada a aprender a fala padrão & 18 & $95 \%$ \\
\hline A criança é estimulada a aprender noções espaciais & 17 & $89 \%$ \\
\hline \multicolumn{3}{|l|}{ MODELO } \\
\hline Você apresenta os seus amigos ao seu filho & 19 & $100 \%$ \\
\hline A televisão é usada de forma sensata & 15 & $79 \%$ \\
\hline \multicolumn{3}{|l|}{ VARIEDADE } \\
\hline A mãe ou pai faz refeições frequentes com o filho & 19 & $100 \%$ \\
\hline A criança é levada a passeios semanalmente & 18 & $95 \%$ \\
\hline \multicolumn{3}{|l|}{ ACEITAÇÃO } \\
\hline $\begin{array}{l}\text { Os pais evitam o uso de restrição física para educar } \\
\text { o filho }\end{array}$ & 12 & $63 \%$ \\
\hline
\end{tabular}


Com relação à Escala 1, nota-se que os pais relataram oferecer estímulos aos filhos, principalmente nos seguintes aspectos: oferecimento de jogos ou brinquedos que permitem a livre expressão e que encorajam a aprender formas.

$\mathrm{Na}$ Escala 2 observa-se que os pais ofereciam maior estímulo ao encorajar os filhos a falar e a ouvir, além de transmitir sentimentos positivos à criança.

Em relação à Escala 3, obteve-se o maior número de respostas verdadeiras nos aspectos: Conversa com seu filho pelo menos duas vezes por semana em um período de meia hora; Responde verbalmente as solicitações ou questões da criança; e Demonstra carinho ao filho durante meia hora por dia.

Quanto à Escala 4, observou-se que os participantes estimulavam academicamente os filhos na fala padrão e relação espacial.

$\mathrm{Na}$ Escala 5, a maioria dos pais apontou que não tinham problemas em apresentar os filhos para seus amigos e utilizavam a TV de forma sensata.

Quanto a Escala 6, nota-se que 100\% dos participantes levavam a criança para passeios semanalmente e faziam pelo menos uma refeição por dia com os filhos.

$\mathrm{Na}$ Escala 7, os pais demonstraram maior índice de respostas verdadeiras no aspecto Os pais não usaram de restrição fisica.

A Tabela 3 mostra os itens de menor frequência relativa e absoluta da estimulação e apoio familiar à criança com deficiência física.

$\mathrm{Na}$ escala estimulação de aprendizagem, notase que os itens com menor frequência foram em relação à carência em comprar e ler uma revista e/ou jornal no âmbito domiciliar.

Quanto a Escala 2, observa-se que os pais apresentaram menor frequência nos itens: Seu filho pode escolher o que é servido no café da manhã ou no almoço; e Evita transmitir sentimentos negativos à criança.

Em relação a ser responsivo, Escala 3, os participantes não apresentaram respostas de menor frequência de itens verdadeiros, ou seja, abaixo de $60 \%$.

$\mathrm{Na}$ Escala 4, observou-se que os participantes estimulavam, com menor frequência, os seus filhos a aprenderem a ler algumas palavras.

No quesito modelagem (Escala 5), os pais apontaram menor frequência em repreender o filho quando o mesmo demonstra comportamentos agressivos, como bater nos pais quando algo lhe é negado.

Quanto à Escala 6, nota-se que há menor frequência nos itens: Deixam a criança ajudar nas escolhas de alimentos no supermercado; e Encorajam a criança a guardar os brinquedos sem ajuda.
$\mathrm{Na}$ Escala 7, os pais demonstraram menor frequência no aspecto Os pais utilizaram de restrições verbais.

Tabela 3 - Menor frequência relativa e absoluta sobre a estimulação e apoio dos pais aos filhos no ambiente domiciliar

\begin{tabular}{|c|c|c|}
\hline EC-HOME & FA & FR \\
\hline \multicolumn{3}{|l|}{ MATERIAIS DE APRENDIZAGEM } \\
\hline Compra e lê um jornal diário diariamente & 4 & $21 \%$ \\
\hline Possui revistas no lar & 1 & $5 \%$ \\
\hline \multicolumn{3}{|l|}{ ESTIMULAÇÃO DE LINGUAGEM } \\
\hline $\begin{array}{l}\text { É permitido que o filho faça escolha do que é } \\
\text { servido nas refeições }\end{array}$ & 10 & $53 \%$ \\
\hline $\begin{array}{l}\text { Evita transmitir sentimentos negativos à } \\
\text { criança }\end{array}$ & 4 & $21 \%$ \\
\hline \multicolumn{3}{|l|}{ ESTIMULAÇÃO ACADÊMICA } \\
\hline A criança é estimulada a ler & 11 & $58 \%$ \\
\hline \multicolumn{3}{|l|}{ MODELO } \\
\hline $\begin{array}{l}\text { Permite que o filho bata em você ou no } \\
\text { cônjuge e não o repreende }\end{array}$ & 2 & $11 \%$ \\
\hline \multicolumn{3}{|l|}{ VARIEDADE } \\
\hline $\begin{array}{l}\text { Os pais permitem que o filho faça parte da } \\
\text { escolha de alimentos no supermercado }\end{array}$ & 9 & $47 \%$ \\
\hline $\begin{array}{l}\text { Os pais estimulam a criança a guardar os } \\
\text { brinquedos }\end{array}$ & 8 & $42 \%$ \\
\hline \multicolumn{3}{|l|}{ ACEITAÇÃO } \\
\hline Os pais utilizam de restrições verbais & 1 & $5 \%$ \\
\hline
\end{tabular}

\section{DISCUSSÃO}

\section{I) Caracterização da amostra}

Em relação à caracterização dos participantes temse que a idade média geral foi de 29,2 anos. Os autores Rothstein Jr e Beltrame ${ }^{16}$ apontam que quanto mais elevada a idade dos pais maior será sua experiência de vida, o que amplia a consciência sobre a função materna e paterna, como a de protetor do desenvolvimento do filho.

Os participantes da pesquisa, em sua maioria, foram mães ( $\mathrm{n}=17)$. Porém, também, obteve a participação de pais $(\mathrm{n}=2)$. Isso demonstra que provavelmente as mães dedicam grande parte do seu tempo para cuidar dos filhos ${ }^{11,17}$.

Quanto à escolarização dos participantes, tem-se que o maior nível de escolaridade é o ensino médio completo e o menor nível é o analfabetismo.

A escolaridade expõe a população ao aprendizado contínuo e à informação. Ou seja, quanto maior o nível educacional, melhor é o acesso à extensão da informação, o que pode facilitar a compreensão sobre a importância para o desenvolvimento infantil ${ }^{16}$. 
Os participantes deste estudo demonstraram baixo índice de analfabetismo (17,5\%), o que pode ter corroborado para a compreensão dos pais quanto à importância da estimulação do filho no lar.

$\mathrm{O}$ diagnóstico apresentado pela maioria das crianças deste estudo é a PC tipo diparética, que consiste de acometimento principalmente dos membros inferiores, seguido de tetraparético, com acometimento nos quatro membros, e hemiparético, que acomete um lado do corpo. As características da disfunção sensório motora pela PC envolvem alterações do tônus muscular, postura e movimentos, o que pode acarretar em dificuldades no que diz respeito a realização de tarefas comuns, próprias da fase do desenvolvimento ${ }^{16}$, requerendo estímulos constantes e diversificados.

\section{II) Maiores e menores frequências absolutas e relativas sobre $o$ apoio familiar às crianças com deficiência física para de estimulação}

Quanto à estimulação oferecida no ambiente familiar, mais especificamente, com relação aos materiais de aprendizagem, os participantes afirmaram que ofereciam às crianças brinquedos ou jogos que permitem a livre expressão e o aprendizado das formas. Isso pode ter ocorrido devido as características da PC diparética, pois as crianças apresentam maior comprometimento de membros inferiores, o que favorece a interação com atividades de motricidade que exigem mais frequentemente o uso dos membros superiores ${ }^{16}$.

Em relação à menor frequência, os pais apontaram que não tinham jornais e/ou revistas em casa. Materiais que incitam a leitura são ferramentas que podem auxiliar as crianças em atividades escolares. A ausência de modelos que estimule a leitura pode privar o interesse das crianças em conhecer novas perspectivas de mundo, novos interesses e experiências ${ }^{11-12}$

Quanto à estimulação da linguagem, os participantes em sua maioria, demonstraram que encorajavam seus filhos a falar e ouvir, além de transmitir sentimentos positivos à criança.

Alinguagemé uma forma de interação que estabelece o suporte afetivo, importante para o desenvolvimento infantil, devendo ser iniciada precocemente, antes que defasagens ou dificuldades escolares sejam notadas ${ }^{18}$. As crianças participantes tinham média de idade de 5,2 anos e estavam sendo estimuladas com mais frequência nesta questão, o que demonstra que os pais notaram ou obtiveram informação sobre a importância da estimulação da linguagem na primeira infância.
Observa-se que os pais apresentaram menor frequência relativa e absoluta nos itens: $\dot{E}$ permitido que seu filho faça escolha no café da manhã ou no almoço e; Evita transmitir sentimentos negativos.

Participar das atividades cotidianas com os pais auxiliam as crianças em seu desenvolvimento motor, cognitivo e emocional. A falta de participação nas atividades cotidianas da família, seja por falta de tempo ou por dificuldade de planejamento, pode interferir no desempenho da independência e autonomia da criança, o que demonstra que, em alguns quesitos, os pais de crianças com deficiência necessitam de informações sobre a forma de interagir e ensinar seus filhos ${ }^{10}$. Uma forma de interação é a participação nas atividades da vida diária e instrumental em que envolve os pais e filhos, pois permite o estabelecimento de vínculos, para além de estímulos nas diferentes áreas do desenvolvimento ${ }^{2}$.

Outra dificuldade demonstrada pelos participantes é em relação a transmissão de sentimentos negativos na interação com a criança. Tal fato pode ocorrer pela não aceitação da deficiência do filho. Para alguns pais a presença da PC pode gerar diversos sentimentos, reforçados por preconceitos culturais e baixo apoio social ${ }^{11}$.

Em contrapartida, notou-se que os pais indicaram resultados positivos no quesito "ser responsivo", pois apontaram que mantinham proximidade afetiva com os filhos, relatando que estavam constantemente presentes na rotina dos mesmos e que os elogiavam sempre que estavam por perto.

Manter a proximidade faz com que as estratégias de cuidado se tornem mais seguras, pois os pais demonstram que estão mais atentos para identificar as necessidades dos filhos ${ }^{18}$. Ser responsivo é garantir o afeto, a atenção e o carinho, bem como procurar formas não agressivas de estabelecer limites ${ }^{19}$.

Quanto à estimulação acadêmica, nota-se certa preocupação em encorajar a criança nas atividades educativas, como por exemplo, estimular a fala padrão e incentivar o aprendizado em relação à orientação espacial. $\mathrm{O}$ envolvimento dos pais nas atividades escolares dos filhos pode auxiliar nas aquisições de habilidades sociais infantis e no desempenho acadêmico positivo ${ }^{20}$.

No quesito "modelagem", grande parte dos participantes demonstrou que apresentavam seus filhos aos amigos e que a televisão era utilizada de forma adequada. É importante que as mães participem direta e ativamente do processo de modelagem e instalação de repertórios comportamentais com seus filhos ${ }^{19}$.

$\mathrm{Na}$ escala relacionada ao oferecimento de variedades de estimulação, os participantes demonstraram 
maior frequência em estímulos externos, como o passeio, além de participar de uma refeição ao dia com o filho.

Por outro lado, os pais apresentaram menor frequência em permitir que a criança participasse da escolha de alimentos em supermercados e não encorajavam seus filhos a guardar seus brinquedos. Quanto melhor a qualidade da estimulação ambiental (interna e externa) e da interação familiar, melhor será o desempenho cognitivo, emocional e social da criança ${ }^{11}$.

Em relação ao quesito modelo parental, os participantes apontaram dificuldades em impor limites quando o filho demonstrava comportamento desafiador, ao "bater" nos pais para demonstrar descontentamento. Impor limites aos filhos, diante de comportamentos desafiadores, é garantir o afeto, a atenção e o carinho ${ }^{20}$.

A família pode ser considerada como principal modificadora e/ou mantenedora das competências infantis, portanto não agir de maneira responsiva demonstra redução de habilidades educativas parentais, que podem ser prejudiciais para o desenvolvimento infantil e interação da criança com a família ${ }^{21}$. É importante que os genitores participem direta e ativamente do processo de desenvolvimento educacional e instalação de repertórios comportamentais com seus filhos ${ }^{22}$.

Com relação ao item "aceitação", notou-se que a maioria dos pais afirmou que não usam agressão física para repreender o filho. Em contrapartida, apenas 1\% dos participantes relatou utilizar restrição verbal para impor limites comportamentais infantis.

A ausência de punições violentas demonstra que os pais são responsivos e apresentam maior aceitação de seus filhos, o que amplia a probabilidade das crianças terem suas necessidades desenvolvimentais atendidas ${ }^{19,22-23}$.

Por outro lado, acredita-se que, independente da PC, a repreensão verbal é necessária para lidar com possíveis problemas de comportamento da criança ${ }^{22}$.

\section{REFERÊNCIAS}

1. Gianni MA. Paralisia cerebral. In: Teixeira E, Sauron FN, Santos LSB, Oliveira MC. Terapia ocupacional na reabilitação física. São Paulo: Rocca; 2003. p.89-100.

2. Guerzoni VPD, Barbosa AP, Borges ACC, Chagas PSC, Gontijo APB, Eterovick F, Mancini MC. Análise das intervenções de terapia ocupacional nos desempenhos das atividades de vida diária em crianças com paralisia cerebral: uma revisão sistemática da literatura. Rev Bras Saúde Matern Infant. 2008;8(1):17-25. doi 10.1590/S1519-38292008000100003.
A falta de repreensão pode ocorrer pela dificuldade em lidar com algumas dificuldades e comportamentos dos filhos ${ }^{23}$. Além disso, alguns pais, diante do diagnóstico de PC, podem desenvolver sentimentos de compaixão e pena, o que os direciona ao comportamento de superproteção ${ }^{16}$.

A fim de sanar tais dificuldades, faz-se necessário programas que ofereçam apoio aos pais, tornando-os aptos para lidar com as barreiras cotidianas, minimizando suas necessidades e ampliando suas potencialidades ${ }^{24}$.

\section{CONSIDERAÇÕES FINAIS}

Este estudo buscou avaliar a frequência da estimulação e apoio oferecidos à criança no ambiente familiar. A análise dos dados mostrou que os pais estimulam seus filhos e tentam manter-se próximos a eles na maior parte do tempo. Esses comportamentos são importantes para auxiliar no desenvolvimento infantil, assim como em estreitar as relações.

$\mathrm{O}$ estudo procurou fornecer diretrizes, focadas nas famílias, para que compreendam suas necessidades e as de suas crianças, no que se refere a estimulação e desenvolvimento.

Os dados podem auxiliar outras pesquisas na proposição de programas de intervenção focados em famílias e cuidadores de crianças com deficiência física, a fim de maximizar a estimulação que pode ser oferecida aos filhos e capacitar os pais, apontados como os principais agentes para o desenvolvimento infantil, principalmente nos primeiros anos de vida.

E ainda, o presente estudo trouxe a possibilidade do uso do instrumento Inventário EC-Home à profissionais da área da saúde que atuam com famílias de crianças com PC.

3. Oliveira MC, Cordani LK. Correlação entre habilidades funcionais referidas pelo cuidador e nível de assistência fornecida à criança com paralisia cerebral. Arq Bras Paralisia Cerebral. 2004;1(1):24-29.

4. Alegretti ALC, Mancini MC, Schwartzman JS. Estudo do desempenho funcional de crianças com paralisia cerebral diparéticas espásticas utilizando o Pediatric Evaluation of Desability Inventory (PEDI). Arq Bras Paralisia Cerebral. 2004;1(1):35-40. doi: 10.1590/bjpt-rbf.2014.0083. 
5. $\quad$ Brandão MB, Melho APP. Terapia ocupacional em paralisia cerebral. In: Avry VCR, Brandão MB. Reabilitação em paralisia cerebral. Rio de Janeiro: Editora Medbook; 2011.

6. Camargos ACR, Lacerda TTB, Viana SO, et al. Qualidade de vida das mães de crianças e adolescentes com paralisia cerebral. Fisioter Mov. 2010;23(3):389-97. doi: 10.1590/ S0103-51502010000300006

7. Rocha AP, Afonso DRVE, Morais RLS. Relação do desempenho funcional de crianças com paralisia cerebral e qualidade de vida relacionada à saúde de seus cuidadores. Fisioter Pesqui. 2008;15(3):292-7. http://dx.doi.org/10.1590/ S1809-29502008000300013.

8. Souza AP, José-Filho M. A importância da parceria entre família e escola no desenvolvimento educacional. Rev Iberoamericana Educ. 2008;44(7):7-10. Disponível em: http://rieoei. org/1821.htm.

9. Cia F. Estimulação precoce e família: Alguns apontamentos. In: Mendes EG, Almeida MA, organizadores. Dimensões pedagógicas nas práticas de inclusão escolar. Marília: Editora da Associação Brasileira de Pesquisadores em Educação Especial; 2012. p.25-40.

10. Turnbull AP, Turnbull HR. Families, profession al sand exceptionality: collaboration for empowerment. 4th ed. Upper Saddle River, NJ: Merrill; 2001. p.27-48.

11. Azevedo TL. Avaliação multidimensional de um programa de intervenção com mães de crianças com deficiência [dissertação]. São Carlos: Universidade Federal de São Carlos; 2014. Disponível em: https://repositorio.ufscar.br/bitstream/ handle/ufscar/3168/6006.pdf? sequence=1\&isAllowed=y.

12. Gualda DS, Borges L, Cia F. Famílias de crianças com necessidades educacionais especiais: recursos e necessidades de apoio. Rev Educ Especial (UFSM). 2013;26(46):307-30. http://dx.doi.org/10.5902/1984686X5379.

13. Caldwell BM, Bradley RH. Administration home observation for measurement of the environment: administration manual. Temple, AZ: Family \& Human Dynamics Research Institute, Arizona State University; 2003. Available from: Fhdri.clas.asu. edu/home/

14. Martins MFD, Costa JSD, Saforcada ET, Cunha MDC. Qualidade do ambiente e fatores associados: um estudo em crianças de Pelotas. Cad Saúde Pública. 2004;20(3):710-18. http://dx.doi.org/10.1590/S0102-311X2004000300007.

15. Aiello ALR. Instrumentos para avaliação do ambiente familiar visando à inclusão. In: $57^{\mathrm{a}}$ Reunião Anual da SBPC, Fortaleza;
2005. Anais. Disponível em: http://www.reacao.com.br/ programa_sbpc57ra/sbpccontrole/textos/analuciaaiello.htm.

16. Rothstein JR, Beltrame TS. Características motoras e biopsicossociais de crianças com paralisia cerebral. Rev Bras Cien Mov. 2013;21(3):118-26. http://dx.doi.org/10.18511/01031716/rbcm.v21n3p118-126.

17. Santos LF, Cia F. Descrição da opinião dos pais de crianças de diferentes faixas etárias sobre a escolarização e atividades que realizam com os filhos. In: $7^{\circ}$ Congresso Brasileiro Multidisciplinar de Educação Especial, Londrina; 2013. Anais. Inclusão: teoria, prática e produção do conhecimento. Londrina: Universidade Estadual de Londrina; 2013. Disponível em: http://www.uel.br/eventos/congressomultidisciplinar/pages/ arquivos/anais/2013/AT07-2013/AT07-015.pdf.

18. Silva NCB. Contexto familiar de crianças com síndrome de Down: interação e envolvimento paterno e materno [dissertação]. São Carlos: Universidade Federal de São Carlos; 2007. Disponível em: https://repositorio.ufscar.br/bitstream/ handle/ufscar/2960/DissNCBS.pdf?sequence=1\&isAllowed=y.

19. Cia F. Um programa para aprimorar envolvimento paterno: impactos no desenvolvimento do filho [tese]. São Carlos: Universidade Federal de São Carlos; 2009. Disponível em: https://repositorio.ufscar.br/bitstream/handle/ufscar/2854/2353. pdf? sequence $=1$.

20. Pacheco JT, Teixeira MAP, Gomes WB. Estilos parentais e habilidades sociais na adolescência. Psicol Teor Pesqui. 1999;15(2):117-26. Disponível em: http://www.scielo.br/pdf/ ptp/v15n2/a04v15n2.pdf.

21. Del Prette ZAP, Del Prette A. Psicologia das habilidades sociais na infância: teoria e prática. 11a ed. Petrópolis: Vozes; 2005.

22. Silva ATB, Del Prette A, Del Prette ZAP. Relacionamento pais-filhos: um programa de desenvolvimento interpessoal em grupo. Psicol Escolar Educ. 2000;3(3):203-15. doi: 10.1590/ S1413-73722006000100009.

23. Bolsoni-Silva AT, Borelli LM. Treinamento de habilidades sociais educativas parentais: comparação de procedimentos a partir do tempo de intervenção. Estudos e Pesquisas em Psicologia;12(1): 36-58, 2012. Disponível em: http:// www.e-publicacoes.uerj.br/index.php/revispsi/article/ view/8303/6079.

24. Guralnick MJ. Efficacy research in early childhood intervention programs. In: Odom SL, Karnes MB, organizadores. Early intervention for infants and children with handicaps: an empirical base. Baltimore: Brookes; 1998. p.75-88.

Recebido em: 05.09.2016

Aceito em: 30.06.2017 